\title{
Age- and gender-specific silent cardiovascular risk factors in children and adolescents: The PEP family heart study
}

\author{
Gerda-Maria Haas ${ }^{1}$ and Peter Schwandt $\mathbf{t}^{1,2 *}$ \\ ${ }^{1}$ Praeventions-Institut Munich-Nuremberg, Germany \\ ${ }^{2}$ Ludwig-Maximilians University, Munich, Germany
}

\begin{abstract}
Background: Nuclear families are a promising aim for detecting and modifying cardiovascular risk factors. Therefore, we applied simple, inexpensive and risk less anthropometric and laboratory screening procedures to evaluate cardiovascular risk factors in urban families for early intervention.

Subjects and methods: We measured five silent risk factors (hypertension, high triglycerides, high LDL-, high non-HDL-, and low HDL-cholesterol) and two clinical apparent risk factors (general and central adiposity) in 2720 German child-parent pairs. Furthermore, we assessed in 2001 biological child-parent pairs from 852 families height, weight, body mass index, waist circumference, blood pressure, and fasting lipid levels. Within-family associations were calculated using generalized estimating equations (GEE).

Results: All clinical apparent and silent risk factors were significantly correlated between children and their parents. General and abdominal adiposity conferred a significant 2.9-fold and a 2.6-fold enhanced risk among parents of carrying the same risk factors. Similarly, abnormal LDL, HDL, or non-HDL among children conferred a significant 3.0-fold, 2.0-fold, or 2.9-fold increased odds among parents. Among these 412 adolescents with central adiposity, risk factor clustering was 3-4 times more frequent than in the 2626 adolescents without central obesity. Central obesity was the only anthropometric variable that significantly predicted increased risk for all seven non-anthropometric CVD risk factors: hypertension (Odds ratio 2.5), elevated triglycerides (OR 4.9), LDL-C (OR 2.0), non-HDL-C (OR 2.1), triglyceride/HDL-C ratio $\geq 3.5$ (OR 7.2), low HDL-C (OR 1.6), fasting glucose (OR 1.3), and risk factor clustering (OR 3.8). Only general adiposity detected hyperglycemia (OR 1.8) and hypertension (OR 4.9), WHR indicated hypertriglyceridemia (OR 2.3).
\end{abstract}

Conclusions: Cardiovascular risk factors can be easily identified by central adiposity. The inclusion of silent risk factors in a screening of school children might enhance the case-finding potential among their parents.

\section{Introduction}

The American Heart Association (AHA) recommends as Impact Goals 2020 to improve cardiovascular health of all Americans by $20 \%$ [1]. Because the most effective means for avoiding clinical events is to detect cardiovascular disease risk factors (CVDRF) early in life [2]. Because the Australian Busselton Population Health Studies considered the nuclear family as a point of intervention by modifying risk factors [3] we used the families of the Prevention Education Program (PEP) Nuremberg [4] for screening school children for prediction of CVDRF in their parents and adolescents for detecting their CVD risk by screening for silent risk factors [5-8].

The aim of this urban prospective long-term observational study was first to detect cardiometabolic risk factors using easily available, safe, non-invasive and inexpensive traditional measurement procedures and second to intervene by regularly controlled sustained lifestyle change in terms of healthy nutritional intake, leisure time physical activity (LTPA) and non-smoking in young adults and their children.

\section{Subjects and methods}

\section{Study design}

The PEP Family Heart Study is a 15-year prospective communitybased urban study designed to assess and improve cardiovascular health in children and their families through examining CVD risk factors and lifestyle behavior in families [4-6]. The Prevention Education Program (PEP) was approved by the ethical committee for the medical faculty of the Ludwig Maximilians University of Munich (Germany), the Bavarian Ministry of Science and Education, and the local school authorities.

\section{Study population}

We selected 2001 natural child-parent pairs from 852 same household families with complete lifestyle data from the previous study of volunteer biological families [7,8]. The 2690 individuals consisted of 661 fathers (mean age $38.5 \pm 5.2$ years), 833 mothers ( $34.8 \pm 11.1$ years), 614 sons ( $6.8 \pm 1.7$ years), and 582 daughters ( $6.8 \pm 1.7$ years).

\section{Exclusion criteria}

The analysis was restricted to German children and their biological parents to avoid complicating ethnic factors, thus excluding $2.6 \%$ of the participants from 17 other or mixed ethnic groups. Further exclusion criteria were extreme physical activity, special nutritional habits, medication, and clinically apparent cardiovascular, metabolic, endocrine, and malignant diseases.

${ }^{\star}$ Correspondence to: Peter Schwandt, Ludwig-Maximilians University, Munich, Germany, E-mail: API.Schwandt.Haas@t-online.de

Received: May 25, 2018; Accepted: June 12, 2018; Published: June 15, 2018 


\section{Measurements}

All measurements were performed according to protocols contained in the study manual by regularly trained research assistants $[5,6]$. Briefly, personal and familial medical history, socioeconomic data, medication, smoking habits, and PA were assessed by interviewerassisted questionnaires. Height, weight, waist circumference (WC), and blood pressure (BP) were measured; body mass index (BMI) and waistto-height ratio (WHtR) were calculated. Fasting lipid concentrations were measured as previously described [5].

\section{Definition of CVD risk factors}

CVD risk factors were defined as previously described $[7,8]$ for adults/children: overweight, $\mathrm{BMI} \geq 25$ to $\leq 30 \mathrm{~kg} / \mathrm{m} 2$ (86th to $95^{\text {th }}$ percentile); general obesity, $\mathrm{BMI} \geq 30 \mathrm{~kg} / \mathrm{m}^{2}$ ( $>95$ th percentile); abdominal adiposity, $\mathrm{WC}>102 \mathrm{~cm}$ in males, $>88 \mathrm{~cm}$ in females ( $\geq 90$ th percentile); hypertension, BP $\geq 130 / 85 \mathrm{mmHg}$ ( $\geq 95^{\text {th }}$ percentile); dyslipidemia: triglycerides $\geq 150 \mathrm{mg} / \mathrm{dL}$ in males, SBP and/or DBP $\geq 110 \mathrm{mg} / \mathrm{dL}$ in females; LDL-cholesterol (LDL-C) $\geq 130 \mathrm{mg} / \mathrm{dL}$ in males, $\geq 110 \mathrm{mg} / \mathrm{dL}$ in females; HDL-cholesterol (HDL-C) $<40 \mathrm{mg} / \mathrm{dL}$ in males, $<50 \mathrm{mg} / \mathrm{dL}$ in females; non-HDL-C $\geq 160 \mathrm{mg} / \mathrm{dL} \geq 123 \mathrm{mg} / \mathrm{dL}$. To convert cholesterol to millimol per liter, multiply by 0.0259 , and to convert triglycerides to millimol per liter, multiply by 0.0113 .

\section{Statistical analysis}

All statistical analyses were performed in PASW 17.0 (SPSS Inc., Chicago, Illinois) according to a predefined analysis plan and program. Bivariate and multivariate analyses were implemented, and multivariate regression analysis was used for age and gender adjustments or confounders. As some families had more than one child in the analysis and/or child pairs with both the biological father and mother, generalized estimating equations (GEE) $[8,9]$ were used to generate adjusted p-values that accounted for correlation among multiple within-family observations and adjusted for child age and parent age and gender. GEE based on the binomial distribution and log it was used to estimate age and gender odds ratios (OR) for child-parent associations for lifestyle parameters categorized as discrete variables. Analyses were also stratified by child-parent pairs and specified between-subject gender associations by calculating estimated marginal means $[9,10]$. All statistical tests were two-sided, and p-values less than 0.05 were considered statistically significant.

\section{Results}

In this community-based study $83 \%$ of fathers, $60.4 \%$ of mothers, $19.7 \%$ of sons, and $40.7 \%$ of daughters had at least one cardiovascular risk factor, while $56.6 \%$ of fathers, $28.6 \%$ of mothers, $3.9 \%$ of sons, and $7.8 \%$ of daughters had two or more risk factors. The most prevalent cardiovascular risk factors were hypertension (54.9\%) in fathers, high WC $(32.2 \%)$ in mothers, high non-HDL-cholesterol (13.2\% in sons and $18.4 \%$ in daughters) and high LDL-C (12.5\%) in sons and $17.8 \%$ in daughters.

Among the 2,270 parents and children all correlations between silent and overt risk factors were highly significant $(\mathrm{p}<0.01)$ as shown in Table 1. We observed the strongest correlations for the silent risk factors LDL-cholesterol, HDL-cholesterol, and non-HDL cholesterol.

Three silent and two clinical apparent age- and gender-adjusted cardiovascular risk factors among 1,559 children were associated with a significantly 2-3-fold higher association among parents for the same risk factors (Table 2). Parents of children with abnormal LDLcholesterol had a 2.99 -fold increased odds of having abnormal LDLcholesterol (OR 2.99)

We found similar results for abnormal HDL-cholesterol (OR 1.99), and abnormal non-HDL-cholesterol (OR 2.90). Parents of obese children had a 2.91-fold enhanced odds of being obese (OR 2.91), and parents of children with an abnormal WC had a 2.55 -fold enhanced odds of carrying the same risk factor (OR 2.55).

Analyzing the data gender-specifically the odds of having a clinical apparent risk factor appeared to be somewhat higher if the child-parent pair had the same gender. Fathers of obese sons had a 3.8-fold (95\% CI

Table 1. Correlations between cardiovascular risk factors for children and parents as continuous variables

\begin{tabular}{|c|c|c|c|c|c|}
\hline & Father-Son & Father-Daughter & Mother-Son & Mother-Daughter & Parents-Children \\
\hline & $n=603$ & $n=606$ & $\mathrm{n}=\mathbf{7 5 2}$ & $n=759$ & $\mathbf{n}=\mathbf{2 7 2 0}$ \\
\hline Body Mass Index & $0.16^{* *}$ & $0.17 * *$ & $0.23 * *$ & $0.31 * *$ & $0.22 * *$ \\
\hline Waist Circumference & $0.19^{* *}$ & $0.20^{* *}$ & $0.22 * *$ & $0.26^{* *}$ & $0.17 * *$ \\
\hline Systolic Blood Pressure & $0.15 * *$ & $0.12 * *$ & $0.25 * *$ & $0.21 * *$ & $0.17 * *$ \\
\hline Diastolic Blood Pressure & $0.08 * *$ & $0.09 * *$ & $0.16 * *$ & $0.16^{* *}$ & $0.11 *$ \\
\hline Triglycerides & 0.07 & $0.16^{* *}$ & $0.09 *$ & $0.19 * *$ & $0.11 * *$ \\
\hline LDL-Cholesterol & $0.34 * *$ & $0.38 * *$ & $0.31 * *$ & $0.22 * *$ & $0.28 * *$ \\
\hline NonHDL-Cholesterol & $0.34 * *$ & $0.32 * *$ & $0.28 * *$ & $0.23 * *$ & $0.26 * *$ \\
\hline HDL-Cholesterol & $0.17 * *$ & $0.15^{* *}$ & $0.29 * *$ & $0.24 * *$ & $0.20 * *$ \\
\hline
\end{tabular}

CV: indicates cardiovascular; LDL: low-density lipoproteins; HDL: high-density lipoproteins

$* p<0.05$

$* * p<0.01$

Table 2. Age-and gender-adjusted odds ratios for parents based on CVD risk factors in children

\begin{tabular}{|l|c|c|c|c|}
\hline Children with & n & Odds Ratio & $\mathbf{9 5 \%}$ CI & PV(+) \\
\hline Obesity & 145 & 2.91 & $1.96-4.34$ & 19.6 \\
\hline High WC & 146 & 2.55 & $1.80-3.62$ & 17.5 \\
\hline Hypertension & 83 & 1.30 & $0.89-1.90$ & 92.3 \\
\hline High Triglycerides & 95 & 1.38 & $0.92-2.07$ & 7.4 \\
\hline Low HDL-C & 458 & 1.99 & $1.61-2.46$ & 36.2 \\
\hline High LDL-C & 236 & 2.99 & $2.36-3.79$ & \\
\hline High NonHDL-C & 430 & 2.90 & $2.12-3.96$ & \\
\hline
\end{tabular}

CVD: indicates cardiovascular disease; +: positive and -: negative predictive value (PV); HDL: high-density lipoproteins; LDL: low-density lipoproteins 
1.91-747) increased risk of being obese, while mothers of obese sons had a 2.6-fold (95\% CI 1.27-5.39) increased risk of being obese. Similarly, the risk of mothers of obese daughters being obese was 4.0 -fold $(95 \%$ CI 2.14-7.89) while fathers of obese daughters had a non- significant 1.3 -fold (95\% CI 0.48-3.31) increased odds of being obese. The pattern was somewhat similar, although less pronounced, for abnormal waist circumference. Concerning the silent risk factors the odds are not much different: Fathers of sons with increased LDL-C had a 3.7-fold (95\% CI 2.09-6.41) increased odds of having increased LDL-cholesterol and similar risk (OR 3.5; 95\% CI 2.07-6.01) of having increased nonHDL-cholesterol. Similarly, mothers of dyslipoproteinemic sons had increased odds for low HDL-cholesterol (OR 3.3), increased LDLcholesterol (OR 3.5) and increased non-HDL-cholesterol (OR 3.4). Fathers of dyslipoproteinemic daughters had an increased odds having elevated LDL-cholesterol (OR 3.4) and elevated Non-HDL-cholesterol (OR 3.2) while mothers of dyslipoproteinemic daughters had lower odds of having elevated LDL-cholesterol (OR 2.3) and lower HDLcholesterol (OR 2.1). Prevalence of hypertension among children was small, and none of the sex specific or gender-adjusted comparisons reached significance with odds ratios ranging between 0.96 and 1.63 .

Among 3,038 adolescents cardio-metabolic risk variables are presented in Table 3. Mean BMI $(20.5 \mathrm{~kg} / \mathrm{m} 2)$ as an indicator of general adiposity and mean WHtR $(0.44 \pm 0.05)$ as a component of central adiposity were identical in both genders. Compared with females, males had significantly higher WC, WHR, and blood pressure. Hip circumference and lipid levels were higher in females compared to males.

Compared with 2,626 adolescents without central obesity, the prevalence of non-anthropometric risk factor clustering was three times higher in 412 centrally obese adolescents (Table 4). Approximately half of the centrally obese adolescents roughly a quarter had a BMI at or above the 90th percentile.

Age- and gender-adjusted odds ratios for the five anthropometric variables that were increased (waist circumference, body mass index, waist/height ratio, waist/hip ratio and central adiposity) as well as six non-anthropometric risk factors that were abnormal are shown in Table 5. Contrary to the five other anthropometric measures, central adiposity was the only predictor of all silent risk factors, indicating a 1.6 to 7.2-fold higher risk for dyslipidemia and hypertension as well as a 2.7 (95\%CI 1.6-4.-6) times higher risk for increased WHtR. Furthermore, we found a significant positive linear association between the degree of risk factors and central adiposity with age- and gender-adjusted regression coefficients of 0.156 for WHtR and of 0.115 for WC. General

Table 3. Anthropometric and laboratory variables in 3038 German adolescents aged 12-18 years

\begin{tabular}{|c|c|c|c|c|c|c|}
\hline & & Males & & & Females & \\
\hline \multicolumn{7}{|l|}{ Variables } \\
\hline & $\mathbf{n}$ & mean & SD & $\mathbf{n}$ & mean & SD \\
\hline Age (years) & 1639 & 14.3 & 1.9 & 1399 & 14.3 & 1.9 \\
\hline Body Mass Index $\left(\mathrm{kg} / \mathrm{m}^{2}\right)$ & 1633 & 20.5 & 3.2 & 1384 & 20.5 & 3.2 \\
\hline Waist Circumference $(\mathrm{cm})$ & 1633 & $74.0^{*}$ & 9.3 & 1393 & 71.4 & 9.3 \\
\hline Hip Circumference (cm) & 1633 & 89.0 & 9.2 & 1393 & $91.0 *$ & 8.5 \\
\hline Waist-to-Hip-Ratio & 1633 & $0.83^{*}$ & 0.05 & 1393 & 0.78 & 0.06 \\
\hline Waist-to-Height-Ratio & 1633 & 0.44 & 0.05 & 1391 & 0.44 & 0.05 \\
\hline Systolic Blood Pressure (mm Hg) & 1634 & $114.7^{*}$ & 11.5 & 1393 & 109.5 & 9.3 \\
\hline Diastolic Blood Pressure (mm Hg) & 1634 & $71.5^{*}$ & 8.0 & 1393 & 69.7 & 7.8 \\
\hline Total Cholesterol 8mg/dL) & 1638 & 153 & 27.7 & 1399 & $161.9^{*}$ & 29.3 \\
\hline Low DensityLipoprotein-C (mg/dL & 1638 & 86.8 & 24 & 1399 & $91.6^{*}$ & 25.4 \\
\hline High Density lipoptotein C (mg/dL) & 1639 & 52.2 & 11.3 & 1399 & $55.1 *$ & 11.3 \\
\hline NonHDL-C (mg/dL) & 1638 & 100.7 & 27.6 & 1399 & 106.8 & 27.5 \\
\hline Triglycerides (mg/dL) & 1639 & 69.7 & 29.5 & 1399 & $76.1 *$ & 32.9 \\
\hline Ratio Triglycerides /HDL-C & 1639 & 1.43 & 0.78 & 1399 & 1.47 & 0.86 \\
\hline
\end{tabular}

HDL: High density lipoproteins, C: Cholesterol. * $\mathrm{p}<0.05$ significant between genders

Table 4. Age-adjusted prevalence of cardio-metabolic risk factors in 3038 adolescents with and without central obesity ${ }^{\mathrm{a}}$

\begin{tabular}{|c|c|c|c|c|}
\hline & Central Obesity a & & Central Obesity a & \\
\hline & Males without & with & Females without & with \\
\hline & $n=1414$ & $n=225(13,7 \%)$ & $\mathrm{n}=1212$ & $187(13,4 \%)$ \\
\hline & $\mathbf{n}$ & $\mathbf{n}$ & $\mathbf{n}$ & n \\
\hline WC $\geq 90$ th ptl. & 0 & $189(84.0 \%)$ & 0 & $128(68.4 \%)$ \\
\hline $\mathrm{WHtR} \geq 0,5$ & 0 & $174(77.3 \%)$ & 0 & $174(93.0 \%)$ \\
\hline BMI $\geq 90$ th ptl. & 4 & $62(27.6 \%)$ & 14 & $50(26.7 \%)$ \\
\hline Hypertension b & 118 & $35(15.6 \%)$ & 45 & $24(12.8 \%)$ \\
\hline NonHDL-C $\geq 126 \mathrm{mg} / \mathrm{dL}$ & 193 & $62(27.6 \%)$ & 227 & $56(29.9 \%)$ \\
\hline $\mathrm{HDL}-\mathrm{C} \leq 40 \mathrm{mg} / \mathrm{dL}$ & 157 & $35(15.6 \%)$ & 59 & $16(8.6 \%)$ \\
\hline $\mathrm{LDL}-\mathrm{C} \geq 130 \mathrm{mg} / \mathrm{dL}$ & 55 & $21(9.3 \%)$ & 73 & $17(9.1 \%)$ \\
\hline $\mathrm{TG} \geq 150 \mathrm{mg} / \mathrm{dL}$ & 19 & $13(5.8 \%)$ & 28 & $21(11.2 \%)$ \\
\hline TG/HDL-C $\geq 3,5$ & 4 & $4(1.8 \%)$ & 5 & $6(3.2 \%)$ \\
\hline$\geq 3$ CVD risk factors & 47 & $24(10.7 \%)$ & 34 & $20(10.7 \%)$ \\
\hline
\end{tabular}

LDL-C: low density lipoprotein cholesterol; HDL: high density lipoprotein cholesterol; TG: triglycerides

${ }^{a} \mathrm{WC} \geq 90$ th percentile and/or $\mathrm{WHtR} \geq 0.5$

${ }^{\mathrm{b}}$ Systolic and/or diastolic blood pressure $\geq 95$ th percentile

'Non anthropometric 
Table 5. Age- and gender-adjusted significant $(\mathrm{p}<0.05)$ odds ratios and $95 \%$ confidence interval between cardio-metabolic risk factors and waist circumference $($ WC), body mass index (BMI), waist-to-height ratio (WHtR), waist-to-hip ratio (WHR) in 3038 adolescents

\begin{tabular}{|c|c|c|c|c|c|}
\hline & WC & BMI & WHtR & WHR & Central obesity \\
\hline \multicolumn{6}{|l|}{ All $(\mathrm{n}=3038)$} \\
\hline $\mathrm{LDL}-\mathrm{C} \geq 130 \mathrm{mg} / \mathrm{dL}$ & $1.7(1.1-2.8)$ & & $3.0(1.7-5.3)$ & & $2.0(1.4-2.9)$ \\
\hline $\mathrm{HDL}-\mathrm{C} \leq 40 \mathrm{mg} / \mathrm{dL}$ & & & & & $1.6(1.1-2.2)$ \\
\hline $\mathrm{TG} \geq 150 \mathrm{mg} / \mathrm{dL}$ & & & & $2.3(1.2-4.4)$ & $4.9(3.1-7.7)$ \\
\hline TG/HDL-C $\geq 3,5$ & $6.1(1.9-19.8)$ & & & & $7.2(2.9-17.9)$ \\
\hline NonHDL-C $\geq 126 \mathrm{mg} / \mathrm{dL}$ & & & $2.7(.8-4.0)$ & & $2.1(1.7-2.7)$ \\
\hline Hypertension & & $4.9(2.8-8.4)$ & & & $2.5(1.8-3.5)$ \\
\hline$\geq 3$ CVD non anthrop. & & & $2.7(1.6-4.6)$ & & $3.9(2.6-5.5)$ \\
\hline
\end{tabular}

Central adiposity was defined as WC in or above the 90 th percentile and/or WHtR $\geq 0.5$

adiposity in terms of increased BMI predicted hypertension (OR 4.9), WC predicted an elevated TG/HDL-C ratio (OR 6.1), LDL-C (OR 1.7), and WHtR indicated elevated LDL-C (3.0) and non-HDL-C (OR 2.7). Thus, central adiposity in terms of combined measurement of WHtR and WC detected all silent cardio-metabolic risk factors.

\section{Discussion}

Recent studies suggest that cardiovascular disease begins during childhood [11]. Therefore, the family is an optimal target for early detection of cardiovascular risk factors $[2,3]$ because children have frequent contact with the health care system while their young parents very often do not. Thus, we could demonstrate that screening of school children for silent risk factors detects risk in their parents where general and abdominal adiposity conferred a significant 2.9-fold and a 2.6-fold enhanced odds among parents of carrying the same risk factors. Reis et al. described correlations of cardiovascular risk factors between 170 child-parent pairs living in the US [12]. However, in this study $69 \%$ of children were black and $52 \%$ were classified overweight or obese. Regarding public health practice, the early age focus of universal cardiovascular screening may be appealing as screening of school children is in place in many Western countries, while adults are less likely to receive regular screening exams. In addition, the high prevalence of children with at least one cardiovascular risk factor, the growing obesity epidemic in children of Western countries, and the correlation of risk between children and parents observed in this large study support screening efforts in children.

Greater central fat deposition determined by dual-energy X-ray absorptiometry is associated with less favourable plasma lipid profile and blood pressure [13]. In the present study, central adiposity, in terms of increased WHtR and/or increased WC in or above the $90^{\text {th }}$ percentile, significantly predicted an increased risk of risk factor clustering (OR 3.8). The prediction of an increased TG/HDL-C ratio (OR 7.2) might have additional importance as a sign for insulin resistance. Iranian [14] adolescents, BMI, WC, and WHtR were shown to comparably detect cardio-metabolic risk factors. The Bogalusa Heart Study [15] found a similar association of BMI and WHtR with CVD risk factors, and WC was shown to be a better predictor of risk than WHtR and BMI in Greek-Cypriote children [16]. WHtR was the most significant predictor of TG, LDL-C, and Apo A-I levels in a multiple regression analysis of five anthropometric indices in Japanese school children [17]. Increased WC was independently associated with CVD risk factors in Italian children [18] and strongly correlated with the percentage of fat and CVD risk factors in US children [10]. In Chinese children, WC was associated most strongly with TG, HDL-C, and BP, but only weakly with LDL-C, and insignificantly with glucose [20].

\section{Strengths and limitations}

The strengths of this urban study performed in the city of Nuremberg is the homogeneous German population, the large sample size, which has adequate power to detect potentially smaller, but significant relationships. Further strengths are the mono-ethnicity, the gender balance and the use of simple, well-established surrogate methods that permit easy and inexpensive use in any health care practice. Furthermore, the continuously trained study staff, which changed by less than $11 \%$ over the course of ten years, used the same laboratory equipment and external quality-controlled procedures. The limitations of this observational study include the cross-sectional design that does not permit the conclusion of causality from the associations. Furthermore, central obesity was not measured with imaging techniques. Our results are restricted to German children with a relatively low prevalence (4.5-4.9\%) of general and abdominal obesity in both genders. This may have caused a conservative bias, especially if we compare our results to the biracial and high-risk children enrolled in the smaller US study [12].

\section{Conclusions}

Our study suggests that screening elementary school children for cardio-metabolic risk factors may be an efficient case-finding strategy for families allowing for early intervention in children and parents. Notably, $19.7 \%$ of boys, and $40.7 \%$ of girls had at least one cardiovascular risk factor, plus their risk conferred a 2-4-fold risk among their parents. As ultimately, the decision of who to screen for cardiovascular risk factors is based on available sources, the focus on children appears attractive. Optimally, the screening effort may include a blood test for silent risk factors among children to enhance efficacy of the family case finding screening effort. The inclusion of silent risk factors in a screening program of children may be warranted for the high prevalence among children and enhance case-finding potential among parents.

\section{Acknowledgements}

We thank the families who have participated in this study for many years for their outstanding cooperation and we gratefully acknowledge the excellent work and engagement of the study staff, the many physicians and nurses. The PEP Family Heart Study was supported by the Foundation for the Prevention of Atherosclerosis; the City of Nuremberg, Germany; the Ludwig Maximilians University, Munich, Germany; the Bavarian Ministry of Health and Social Affairs and the Ministry of Science and Education, Munich; the AOK Bavaria Munich, Germany, the LVA Oberbayern, Ober- und Mittelfranken, Sparkasse Nuremberg, Friedrich-Baur-Stiftung, Bannss-Stiftung and many others. 


\section{References}

1. Lloyd-Jones DM, Hong Y, Labarthe D, Mozaffarian D, Appel LJ, et al. (2010) Defining and setting national goals for cardiovascular health promotion and disease reduction: the American Heart Association's strategic Impact Goal through 2020 and beyond. Circulation 121: 586-613. [Crossref]

2. Kavey RE, Daniels SR, Lauer RM, Atkins DL, Hayman LL, et al. (2003) American Heart Association guidelines for primary prevention of atherosclerotic cardiovascular disease beginning in childhood. Circulation 107: 1562-1566. [Crossref]

3. Knuiman MW, Divitini ML, Welborn TA, Bartholomew HC (1996) Familial correlation, cohabitation effects and heritability for cardiovascular risk factors. Ann Epidemiol 6: 188-194. [Crossref]

4. Schwandt P, Haas GM (2018) What do we learn from the PEP Family Heart Study about lifestyle-change, blood pressure and lipids in children and their parents? Int $J$ Prev Med.

5. Schwandt P, Geiss HC, Ritter MM, Üblacker C, Parhofer KG, et al. (1999) The Prevention Education Program (PEP). A prospective study of the efficacy of familyoriented life style modification in the reduction of cardiovascular risk and disease: design and baseline data. J Clin Epidemiol 52: 791-800. [Crossref]

6. Geiss HC, Parhofer KG, Schwandt P (2001) Parameters of childhood obesity and their relationship to cardiovascular risk factors in healthy prepubescent children. Int J Obes Relat Metab Disord 25: 830-837. [Crossref]

7. Schwandt P, Bischoff-Ferrari HA, Staehelin HB, Haas GM (2009) Cardiovascular risk screening in school children predicts risk in parents. Atherosclerosis 205: 626-631. [Crossref]

8. Schwandt P, Bertsch T, Haas GM (2010) Anthropometric screening for silent cardiovascular risk factors in adolescents: The PEP Family Heart Study. Atherosclerosis 211: 667-671. [Crossref]

9. Liang KY, Zeger SL (1986) Longitudinal analysis by using generalised linear models. Biometrika 73: 13-22.
10. Zeger SL, Liang KY (1986) Longitudinal data analysis for discrete and continuous outcomes. Biometrics 42: 121-130. [Crossref]

11. Li S, Chen W, Srinivasan SR, Bond MG, Tang R, et al. (2003) Childhood cardiovascula risk factors and carotid vascular changes in adulthood: the Bogalusa Heart Study. JAMA 290: 2271-2276. [Crossref]

12. Reis EC, Kip KE, Marroquin OC, Kiesau M, Hipps L Jr, Peters RE, et al. (2006) Screening children to identify families at increased risk for cardiovascular disease. Pediatrics 118: 1789-1797. [Crossref]

13. Daniels SR, Morrison JA, Sprecher DL, Khoury P, Kimball TR (1999) Association of body fat distribution and cardiovascular risk factors in children and adolescents. Circulation 99: 541-545. [Crossref]

14. Kelishadi R, Gheiratmand R, Ardalan G, Adeli K, Mehdi Gouya M, et al. (2007) Association of anthropometric indices with cardiovascular disease risk factors among children and adolescents: CASPIAN Study. Int J Cardiol 117: 340-348. [Crossref]

15. Freedman DS, Kahn HS, Mei Z, Grummer-Strawn LM, Dietz WH, et al. (2007) Relation of body mass index and waist-to-height ratio to cardiovascular disease risk factors in children and adolescents: the Bogalusa Heart Study. Am J Clin Nutr 86: 3340. [Crossref]

16. Savva SC, Tornaritis M, Savva ME, Kourides Y, Panagi A, et al. (2000) Wais circumference and waist-to-height ratio are better predictors of cardiovascular disease risk factors in children than body mass index. Int J Obes Relat Metab Disord 24: 14531458. [Crossref]

17. Hara M, Saitou E, Iwata F, Okada T, Harada K (2002) Waist-to-height ratio is the best predictor of cardiovascular disease risk factors in Japanese schoolchildren. $J$ Atheroscler Thromb 9: 127-132. [Crossref]

18. Maffeis C, Pietrobelli A, Grezzani A, Provera S, Tato L (2001) Waist circumference and cardiovascular risk in prepubertal children. Obesity Res 9: 179-187. [Crossref]

19. Higgins PB, Gower BA, Hunter GR, Goran MI (2001) Defining health-related obesity in prepubertal children. Obes Res 9: 233-240. [Crossref]

20. Sung RY, Yu CC, Choi KC, McManus A, Li AM, Xu SL, et al. (2007) Waist circumference and body mass index in Chinese children: cutoff values for predicting cardiovascular risk factors. Int J Obesity 31: 550-558. [Crossref]

Copyright: (C2018 Haas G. This is an open-access article distributed under the terms of the Creative Commons Attribution License, which permits unrestricted use, distribution, and reproduction in any medium, provided the original author and source are credited. 